UNIVERSUM • Vol. $30 \bullet$ No $1 \cdot 2015 \bullet$ Universidad de Talca

Música, sociedad y modernidad: La vida artística de la ciudad de Talca en torno a sus teatros y corporaciones filarmónicas durante la temprana República (1837-1874)

José Miguel Ramos - Gonzalo Martínez

Pp. 217 a 231

\title{
MÚSICA, SOCIEDAD Y MODERNIDAD: LA VIDA ARTÍSTICA DE LA CIUDAD DE TALCA EN TORNO A SUS TEATROS Y CORPORACIONES FILARMÓNICAS DURANTE LA TEMPRANA REPÚBLICA (1837-1874)
}

\author{
Music, society and modernity: The city of Talca's artistic life around its theatres and \\ philharmonic societies during the early republic (1837-1874)
}

\author{
José Miguel Ramos* \\ Gonzalo Martínez**
}

\section{RESUMEN}

El presente trabajo pretende acercarnos a comprender la dinámica social producida en torno a la actividad en teatros y sociedades musicales de la ciudad de Talca durante el siglo XIX, dando cuenta de fenómenos de vinculación y marginación de grupos y espacios determinados, que a través del desarrollo principalmente de repertorio de tipo operístico, comparten la mirada transformadora que sugiere el bien modernizador de la música.

Palabras clave: Talca, siglo XIX, teatros, corporaciones filarmónicas, modernidad.

\section{ABSTRACT}

The current work is aimed to understanding the social dynamics produced around the activity in theaters and musical societies of the city of Talca in the nineteenth century, realizing phenomena of linkage and marginalization of particular groups and spaces, which

\footnotetext{
* Facultad de Arquitectura, Música y Diseño, Escuela de Música, Universidad de Talca. Talca, Chile. Correo electrónico: jramos@utalca.cl

** Facultad de Arquitectura, Música y Diseño, Escuela de Música, Universidad de Talca. Talca, Chile. Correo electrónico: gmartinez@utalca.cl
}

Artículo recibido el 30 de diciembre de 2013. Aceptado el 20 de agosto de 2014. 
through the development of repertoire of primarily operatic type, share the transformative gaze that suggests the music's modernizing benefit.

Keywords: Talca, Nineteenth century Theater, philharmonic corporations, modernity.

\begin{abstract}
"Sabemos que los artesanos de nuestro pueblo a fin de cultivar el espiritu de asociación $y$ de fraternidad, piensan organizar una sociedad de filarmónica para pasar las largas noches de invierno. Celebramos con entusiasmo esta idea que los honra altamente. Que dirá nuestra juventud elegante cuando los pobres artesanos saben proporcionarse entretenciones honestas, propias de la jente culta i de alto tono"'.
\end{abstract}

De esta manera la editorial del periódico El obrero Católico, se refería a un fenómeno que despertaba la atención y asombro de la sociedad talquina de la época. Es que la discursividad de las clases hegemónicas, que es propia de una sociedad de raigambre agraria e incipientemente industrial, se asienta en un querer verse reflejada en lo europeo como referente de modernidad. Pero la cita además nos muestra con claridad la visión moralizadora que se vincula a la actividad artística de este tipo, entendiendo que toda asociatividad de esta especie, es propia sólo de los círculos "cultos y elegantes" y es extraña a los sectores subalternos, que en este caso, corresponden a los miembros de la Sociedad Filarmónica de Artesanos.

La actividad artística en la ciudad ha estado siempre presente, en especial la que se ha relacionado con manifestaciones en espacios públicos, cuyas representaciones teatrales pueden ser documentadas desde el periodo colonial. Los entremeses, sainetes y loas preparados para la visita del Capitán General a la ciudad en 1796 y otras actividades referidas a festividades civiles y religiosas así lo atestiguan $^{2}$.

Durante la primera República, específicamente en el espacio de tiempo que el estudio aborda, la ciudad de Talca fue escenario de numerosos hechos de relevante importancia en el establecimiento de un modelo de Estado que se caracterizaría por un desarrollo en forma orgánica sobre la base del régimen político instituido por Portales y bajo la dirección de sectores conservadores de la clase dirigente. El poder y el prestigio de la oligarquía de la época, descansaban principalmente en la minería en el norte, y en la gran propiedad agrícola en la zona centro-sur, en donde muchos de los principales personajes públicos de la ciudad tenían puesta su fortuna. Pero sobre todo la historia de la ciudad manifiesta a través de sus expresiones artísticas,

\footnotetext{
${ }^{1}$ El Obrero Católico, 25 de junio de 1868.

${ }^{2}$ Ver Ramos Fuentes, José. "Música y sociedad en Talca antes del Concilio Vaticano II: Una aproximación histórico-social (1857-1916)”, Espacio Regional 9/1 (2012): 93-107.
} 
un mirarse a sí misma deseosa de ser un modelo de modernidad y progreso, en un plano imaginario que según Glissant "es la construcción simbólica mediante la cual una comunidad (racial, nacional, imperial, sexual etc...) se define a sí misma”3. Esta construcción simbólica, se enmarca en los preceptos del republicanismo ilustrado que se instaura a partir del gobierno de Bulnes y que se ve representado en el discurso que la sociedad talquina intentará plasmar a través de la dinámica sociocultural en torno a su actividad musical, en especial la vinculada a los teatros.

Uno de los aspectos relevantes del proyecto ilustrado de la modernidad, tiene relación con que el inicio de la actividad musical en espacios públicos a partir de las primeras décadas del siglo XIX, se manifiesta como un elemento democratizador del bien simbólico de la música y de la literatura, los que se entrecruzan en géneros como la ópera y el canto acompañado. Por esto, los discursos emanados desde las élites, permanentemente vincularán el bien simbólico de la democracia con el cultivo de las virtudes morales que acarrea la ilustración y la modernidad, siendo enérgicos en que todo pueblo que al menos pretenda acercarse al ideal del ser "culto y civilizado", debe ver las luces de la ilustración. Un buen ejemplo de lo anterior se desprende del discurso de incorporación de don José Victorino Lastarria a la Sociedad Literaria de Santiago, en mayo de 1842:

que aun cuando la base de nuestro gobierno es la democracia, le falta todavía el apoyo de la ilustración, de las costumbres y de las leyes. [...] ¿Y cómo conseguirlo? Ilustrándonos para difundir en el pueblo las luces y las sanas ideas morales ${ }^{4}$.

El extracto reproduce de manera fiel el elemento moralizante de la modernidad, en cuanto la ilustración representa la mejor de las banderas en contra de la barbarie representada en la sociabilidad y sensibilidad de las clases populares y que según Salinas se volcó a través de una sociabilidad festiva y callejera ${ }^{5}$. De esta manera, los mencionados sectores, en un polo distante, evocan constantemente una situación de subalternalidad expresada en términos de clase, género, oficio y calidad moral.

Esta distinción entre educado y no (o parcialmente) educado en el aprendizaje de la academia y la moral occidental, conduce a la tradicional

\footnotetext{
${ }^{3}$ Beverley, Jhon. "El subalterno y los límites del saber académico", Subalternity and Representation: Arguments in Cultural Theory. Traducción de Marlene Beiza y Sergio Villalobos-Ruminott. Dhuram: Duke University Press, (1999): 2.

${ }^{4}$ Discurso de Incorporación de don José Victorino Lastarria a una Sociedad Literaria de Santiago, en la Sesión del tres de mayo de 1842.

${ }^{5}$ Al respecto ver Salinas, Maximiliano. "Comida, música y humor. La desbordada vida popular". En Rafael Sagredo y Cristián Gazmuri (eds.), Historia de la vida privada en Chile. El Chile moderno de 1840 a 1925. Tomo II. Buenos Aires: Aguilar, Altea, Taurus, Alfaguara S.A., (2005): 91-117.
} 
polarización con la que es observada la dicotomía de modernidad y barbarie, y que constantemente se manifiesta en un relato de estructura especular. Según García Canclini ${ }^{6}$, este "binarismo maniqueo" plantea lo forzado de reducir todo a la mencionada polaridad, ya que dicha oposición deja fuera de perspectiva la real trascendencia del proceso de hibridación multicultural y la complejidad estructural de la modernidad latinoamericana. En esa perspectiva toma mayor relevancia el citado discurso, ya que en esa ilustración de lo que podríamos llamar subalterno, se produce inevitablemente la hibridación de grupos tradicionalmente estratificados. Lastarria además dice:

Otro apoyo más quiere la democracia, el de la ilustración. La democracia, que es la libertad, no se legitima, no es útil ni bienhechora sino cuando el pueblo ha llegado a su edad madura, y nosotros somos todavía adultos.

\section{LA ACTIVIDAD EN TORNO A LOS TEATROS}

Uno de los espacios que refleja tal hibridación en la ciudad, son justamente los espacios escénicos, que como veremos, según el grupo social al que representen, variarán en diversos aspectos, pero con el denominador común de que quienes los componen, quieren formar parte de un imaginario asentado en los ideales de civilidad e ilustración.

La historia de estos espacios en la ciudad está marcada por los esfuerzos de particulares vinculados a las artes, especialmente inmigrantes italianos, empresarios, y la propia Municipalidad, de querer dotar a la ciudad de un espacio que es imagen de cuán civilizada pudiera ser esta. En 1854, El Eco de Talca, periódico que continuó con la línea editorial del primer periódico de la ciudad, El Alfa, sostiene lo siguiente:

El teatro es el barómetro por el cuál mide el viajero el grado de cultura y civilización a que se hallan colocado los pueblos. Mengua es para Talca, ciudad de primer orden de la República, no poseer este poderoso vehículo de la ilustración moderna ${ }^{7}$.

No deja de ser llamativo que 6 años más tarde, el 6 de octubre de 1860, leamos en el periódico La Esperanza una autocrítica similar:

\footnotetext{
${ }^{6}$ García Canclini, Néstor. El teatro de las identidades. América y Europa: Seducción, suspicacia, confusión, 1999. Disponible en: http://www.etcetera.com.mx/1999/358/ngc358.html.

${ }^{7}$ El Eco de Talca, 11 de noviembre de 1854, n 10, p. 2, c.1 y 2.
} 
[...] ya ha llegado el tiempo en que Talca debe tener un teatro adecuado i en harmonia con su estado de cultura i adelanto. En todos los pueblos del mundo, medianamente adelantados, por lo menos se posee un teatro i no se ahorran esfuerzos por obtenerlo $[\ldots]^{8}$.

Para mencionar los espacios escénicos, o llamados teatros, debemos señalar que el término en la extensa documentación consultada, es usado indistintamente para referirse al espacio propiamente tal en que se desarrolla el arte dramático, al espacio en el que se interpreta música (principalmente de corriente ópera italiana, de cámara o solística) y también a un espacio mixto como lo es el llamado casino o teatro, que en las primeras décadas del siglo además sirve de posada, lugar de riñas de gallos, cancha de bolos y restaurant.

Las primeras noticias en cuanto a teatros propiamente tales, podemos encontrarlas en las numerosas cartas que dirigiera Carmen Arriagada al pintor de origen bávaro Juan Mauricio Rugendas, en las que señala ya en 1836 la presencia y ubicación del café de Santo Domingo, al poniente de la antigua iglesia del mismo nombre, y que será el escenario de las pocas entretenciones a las que tuvo acceso la destacada dama chillaneja. Especial mención merece la información que nos suministra Carmen de la visita de Las Petorquinas en 1837, famosas cantoras que destacaron en las fiestas y chinganas de la época. Además Carmen, describiendo a Rugendas la monotonía de la vida en la ciudad, menciona:

El Teatro sigue, y sigue gustándome: allá voy todos los domingos, y es mi única diversión?.

Además, reiterando su sentir de soledad, relata al pintor que dado que muchas de las personas de su familia están en el campo, tuvo que asistir acompañada por el "Dr. al Teatro", con el disgusto que ello conllevó, al no tener relaciones muy estrechas con la gente del pueblo. Numerosas son las menciones al teatro, que nos hace pensar en lo importante que fueron estás representaciones en una ciudad de provincia aún marcada por la monótona vida colonial, en que Carmen manifiesta que su sentir melancólico y solitario, acrecentado ya que no tiene "piano ni guitarra" 10 .

Por otro lado, la música que se vinculó directa o indirectamente al amplio repertorio de ópera italiana que se compuso durante el siglo XIX, tuvo una tremenda repercusión en las naciones independientes americanas como símbolo de modernidad

\footnotetext{
${ }^{8}$ La Esperanza, 6 de octubre de $1860, \mathrm{n}^{\circ} 8$.

${ }^{9}$ Carta de Carmen Arriagada a Mauricio Rugendas, Talca, enero 28 de 1838.

${ }^{10}$ Ibidem.
} 
de la Europa lejana, que hacia la década de 1830 quería ya ser aproximada como un referente en calidad y puesta a la moda. De este modo, Rossini, Verdi, Bellini y Donizetti son nombres que aparecen muchas veces como símbolo de progreso y actualidad musical, que interpretadas por numerosos artistas europeos que visitan la ciudad, se convierten en un canon estético y cultural para diversos espacios de la sociedad.

La mencionada repercusión conllevó un nivel de civilidad desconocida hasta entonces, en la que los espacios escénicos no se reducirán (en cuanto a masividad se refiere) a fiestas cívicas o religiosas de participación colectiva de los distintos estratos de la sociedad, sino que se verán involucrados en la temprana dinámica capitalista que permitirá acceder a un espectáculo a quien "en términos no del todo claros" pueda pagar una entrada.

Esta dinámica motivó a que sean los mismos artistas los que emprendan la organización más o menos estable de espacios escénicos especializados donde las compañías venidas desde Copiapó, Santiago o Valparaíso pudieran actuar en la ciudad y así fortalecer la autoconciencia ilustrada de la burguesía talquina. El primer antecedente corresponde a la iniciativa del actor Francisco Navarro alrededor de 1854, quien había dirigido o presidido en Santiago un establecimiento de este género, adquiriendo alguna práctica y aptitudes en orden a representaciones dramáticas. Navarro organizó una compañía con noveles actores y actrices construyendo un teatro en la Alameda, frente al antiguo templo de la Merced. La pequeña compañía, según un periódico de la época, se destacaba en las representaciones de obras cómicas como El médico a palos o la Escuela de maridos. El teatro de Navarro funcionó por algunos años sirviendo no sólo a la propia compañía sino también a las de afuera que venían a la ciudad, como la famosa compañía de Jiménez.

La diversidad de expresiones que albergaban estos espacios, hoy nos parece insólita, pero da cuenta de que aún en las primeras décadas del siglo, el concepto de espectáculo artístico está más vinculado a la idea de diversión propia de la Colonia, que de contemplación estética de una obra musical o dramática, como sí se manifestará en las décadas posteriores. El contenido de un programa de teatro del año 1845 así lo testimonia:

"Parte primera: El señor abbdala ejecutará varias pruebas de fuerza y posiciones académicas sacadas del vaticano de Roma.

Parte segunda: La señora abbdala ejecutará sus pruebas admirables de dislocación.

Tercera parte: Se concluirá la función con una divertida Pantomima"11.

Este dato nos permite señalar que Talca, ya en fecha tan temprana, formaba parte del circuito de ciudades por las que trabajaban compañías principalmente

${ }^{11}$ El Alfa, diciembre 6 de 1845, año 2, n 59 , p. 4 c. 2. 
extranjeras. El señor "Abdala” no puede ser otro que Hércules Abdala, director francés de la Compañía del mismo nombre que un año más tarde inaugurará el Teatro El Buitrón de Goyenechea, en Copiapó ${ }^{12}$.

La Compañía Abdala seguramente actuó en el teatro del casino Santo Domingo, un café de larga vida como espacio escénico no solamente teatral, ya que en el que se anuncian además presentaciones musicales de artistas locales y extranjeros, incluso hasta 1862, año en que ya funciona un teatro de grandes proporciones. Otro espacio, aunque esta vez solamente restringido a la música, será el café Italiano, en la calle Cienfuegos, abierto en diciembre de 1846.

La diversidad de diversiones públicas existentes obliga a la Municipalidad a dictar un reglamento, dándonos interesantes aportes de qué se hacía, cómo se regulaba y sobre todo de la importancia que revestía de acuerdo al orden moral impuesto, ya que las diversiones cercanas a las prácticas de la élites (en las cuales seguramente participaban activamente los miembros del honorable consejo) rendían los mayores recursos a las arcas municipales, y las relacionadas a festividades más bien populares, con patentes de poco valor y claramente restringidas. Así todo establecimiento de diversiones públicas dentro del departamento de Talca, debió antes de abrir sus puertas, sacar de la Tesorería Departamental una patente que corresponda a su clase de establecimiento conforme a la clasificación siguiente:

"[...] De $1^{\circ}$ clase, que vale 15 pesos para los teatros, salones ópticos y otros establecimientos de esta especie.

De $3^{\circ}$ clase, que vale 12 pesos para los cafees que hagan uso de villar y para los fondos y chinganas en que haya canto y baile.

Art. $5^{\circ}$ Por cada concierto o baile público, se pagará 12 pesos y si este último fuera de máscaras 80 pesos.

Art $6^{\circ}$ Por cada fonda o chingana que se estableciera orillas del campo de marte en los días de la celebración del 18 de setiembre, pagará un peso diario por cada vara cuadrada de terreno que ocupe, si hubiera venta de licor, y solo 10 centavos diarios por el mismo terreno, si no hubiere dicha venta $[\ldots]]^{\prime \prime 3}$.

La intención de los propios artistas de dotar a la ciudad de un teatro que encierre las condiciones adecuadas para la representación de las compañías, no se reduce a

\footnotetext{
${ }_{12}$ Pereira Salas, Eugenio. Historia del Teatro en Chile desde sus orígenes hasta la muerte de Juan Casacuberta 1849. Santiago de Chile: Editorial Universitaria, (1979): 321.

${ }^{13}$ Acta de la Municipalidad de Talca, publicada en El Eco de Talca, 16 de septiembre de 1854, p. 3 c. 1 y 2 y p. 4 c. 1.
} 
la iniciativa del actor Navarro, ya que luego de variadas y exitosas presentaciones en la ciudad, en 1857 la compañía lírica de los italianos Pablo Ferreti y Hugo Devoti manifiesta su intención de celebrar un contrato con la Municipalidad para construir un teatro. La proposición fue inmediatamente acogida por la autoridad, quién proporcionó un terreno ubicado en la calle 1 oriente, en el número $167^{14}$, y también por particulares, ya que leemos en El Emisario del 19 de diciembre de dicho año, que los italianos:

Ocúpanse de enterar una suscripción que casi espontáneamente la han ofrecido varios sujetos que se esfuerzan porque nuestro pueblo posea un establecimiento de esta especie ${ }^{15}$.

Como vemos, la preocupación por la construcción de un teatro y el modo de financiarla, no estuvo a cargo solamente del gobierno local, sino también de las élites, quienes de esta forma ayudaban en la construcción de un espacio que sería socialmente cerrado. Las palabras de Manuel Vicuña sobre el salón decimonónico pueden bien entenderse con relación al teatro:

Los salones constituyeron verdaderas coyunturas mediante las cuales se artículó, en forma regular, el "tráfico social" de la oligarquía. Quienes sociabilizaron al interior de estos espacios, en atención al carácter exclusivo de los mismos, pusieron en práctica principios de reserva social que, se puede inferir, denotaban un alto grado de autoconciencia grupal ${ }^{16}$.

Este proyecto se vería frustrado por la revolución de 1859. Se había avanzado en la construcción del teatro, pero aún estaba sin terminar. La Municipalidad estuvo discutiendo la posibilidad de derribar lo que se había construido, sin embargo optó por vendérselo al empresario Genaro Silva en $1860^{17}$. Nuevamente comprobamos el interés del público ilustrado en la continuación del anhelado espacio, ya que se propone organizar un baile a beneficio del proyecto, y durante los meses siguientes la prensa informa sobre los avances que Silva hace para poner en condiciones el establecimiento. Sin embargo, es evidente que para la Municipalidad no cumplía con las aspiraciones que tenía sobre las características de un coliseo digno de la ciudad, seguramente por ser privado. El mismo año en que le vende el teatro a

${ }^{14}$ Opazo Maturana, Gustavo. Historia de Talca. Santiago de Chile: Imprenta Universitaria, (1942): 336.

${ }^{15}$ El Emisario, 19 de diciembre de 1857, no 22, p. 2, c.3.

${ }^{16}$ Citado en: Rodríguez Silva, Andrea. "Los orígenes del Teatro en Copiapó. Consumo, placer e instrucción, 1847-1867”. Tesis para optar al grado de Magíster en Historia, Mención en Historia de América. Facultad de Filosofía y Humanidades. Chile: Universidad de Chile, 2003. Disponible en: http://www.tesis.uchile.cl/ tesis/uchile/2003/rodriguez_a/html/index-frames.html [Consultado: el 10 de agosto de 2013].

${ }^{17}$ La Esperanza, 27 de octubre de 1860, no 8, s/p. 
medio construir, acepta la propuesta del farmacéutico italiano Héctor Franzoy para construir uno municipal. La prensa hace eco de este hecho, y nos informa:

Según sus propuestas Franzoy se compromete a entregar concluida la obra en el plazo de tres años, amortizando desde entonces los ocho mil pesos que el vecindario ha facilitado con este objetivo ${ }^{18}$.

Desconocemos las razones por el cual este nuevo intento fracasó, pero sabemos por la prensa que Franzoy estuvo en serios aprietos económicos, llegándose a realizar eventos en beneficio de su persona. Mientras tanto, Talca poseía solo un teatro privado, el de Silva, puesto que el de Navarro fue demolido en 1862, ya que se encontraba en un estado ruinoso ${ }^{19}$.

La precariedad de la construcción en madera, seguramente acentuada por lo extremo del invierno talquino, probablemente conspiró contra la permanencia de edificios de estas características. Durante la década de 1860 es posible encontrar en la prensa noticias que hacen referencia al estado del teatro. Además, es posible que el hecho de haber comprado un edificio a medio terminar, no haya permitido a Silva construir un teatro en las condiciones que la elite talquina exigía. En el informe publicado en 1867 por los ingenieros José Antonio Silva Vergara y José Antonio Fernández Rufat, se reafirma que el edificio está en buenas condiciones. Sin embargo, se sugiere que no se acepte en las galerías a más de 100 o 120 personas y que se refuercen los pilares de los muros ${ }^{20}$. Esto indica que la construcción, relativamente nueva, no cumplía con las características de un gran teatro, a pesar de que se indica que su estado es apto para albergar a 500 espectadores $^{21}$.

Es posible que lo anterior explique que la actividad de las compañías de óperas y variedades haya decaído en el teatro de Talca por esos ańos, ya que en 1868 encontramos en la prensa una nota que, en el fondo, reitera la percepción de la carencia de diversiones y actividades culturales, cuyo contenido recuerda las quejas de Carmen Arriagada, 30 años antes:

Ya hace años que nuestro teatro, escuela de civilización, ilustración y moral está completamente silencioso. Nos vamos acercando a las largas noches de invierno, i no tenemos un lugar donde pasar honrosamente i con placer una hora de diversión. Qué significa esto? A caso Talca se ha propuesto colocarse a la retaguardia de todas las ciudades de la república ${ }^{22}$.

\footnotetext{
${ }^{18}$ La Esperanza, 6 de octubre de 1860, $\mathrm{n}^{\circ} 8$.

${ }^{19}$ La Esperanza, 14 de junio de 1862.

${ }^{20}$ El Artesano, 26 de mayo de 1867, no 27, p. 3, c. 2-3.

${ }^{21}$ Ibid.

${ }^{22}$ El Artesano, 19 de abril de 1868, Ańo 12, no 72, p. 3, c. 3.
} 
Es posible que detrás de este discurso encontremos una conciencia de ser periféricos, de estar a medio camino entre las dos principales ciudades del país, pero no podemos dejar de reiterar que el anhelo de un teatro "digno" de la ciudad denota además el valor simbólico que al arte de la representación, especialmente la ópera, le confería la burguesía decimonónica, siempre mirando a Europa como un espejo en el que reflejarse, para paliar quizás esa conciencia periférica que acabamos de mencionar.

Finalmente, fue gracias al intendente, don Ursicino Opazo Silva, que el proyecto del teatro pudo llevarse a buen puerto, a través, nuevamente, de comprometer recursos municipales y privados. El teatro de Genaro Silva fue demolido en 1872, y en la misma calle se proyectó un edificio municipal, en el lugar que ocupa hoy el Teatro Regional. Se utilizó como referencia los planos del teatro de Quillota. Su construcción no tardó más de 20 meses, iniciándose aproximadamente a fines de 1872 . Una comisión se encargó de recaudar en 4 cuotas las cantidades comprometidas por los vecinos más acaudalados, comisión que contó como tesorero al ingeniero José Antonio Silva Varas, el mismo que asegurara el buen estado del teatro demolido en 1872 .

En una crónica de inicios de 1874 podemos ver que los esfuerzos del gobierno local y la burguesía acaudalada dieron como resultado un imponente edificio para la época:

Nuestro teatro mide 51 metros por 24 i medio de ancho; 15 de alto en el frente i 11 desde el pavimento al cielo entablado, tomándose desde el medio de la platea.

La platea mide 17 metros de largo por 15 1/2 de ancho, pudiendo caber comodamente 400 acientos.

En las dos órdenes de palcos pueden asistir 300 personas sin estrechez ninguna, pues son 41 palcos, mucho mayores aun que los del teatro Municipal de Santiago.

En la galeria que ocupa todo el derredor del teatro, caben 700 asientos, sin incomodidad ninguna.

Con una capacidad para 1400 personas, contaba además con un salón para fumadores, y un salón "de filarmónica". La iluminación era totalmente a gas, y la construcción fue totalmente de cal y ladrillo. Fue inaugurado el 15 de agosto de 1874, un año antes de lo erróneamente afirmado por Opazo Maturana, con La Conquista de Madrid, obra presentada por la compañía Mateos-Catabeni. 


\section{DE LOS TEATROS A LAS SOCIEDADES FILARMÓNICAS}

Una de las principales diferencias que se generan en el ámbito musical chileno entre la Colonia y el siglo XIX, tiene que ver con que en este último se inicia una destacada actividad de conciertos públicos en las principales ciudades del país, actividad que antes de la República, sólo se circunscribió a la tertulia, como espacio de interpretación musical. Es en el siglo XIX, producto de la diversificación de la educación, la importación de partituras e instrumentos musicales y sobre todo la llegada de músicos extranjeros, que la música sobrepasa el ambiente propio del salón y llega a las incipientes clases medias, dando origen a gran cantidad de aficionados con el vivo interés de asociarse y socializar el arte musical con sus pares. "La música que se interpretaba provenía de una vertiente europea, sinfónica de cámara u operática, la que al ser nueva en el país, se vincula con el proyecto democratizador de la modernidad" ${ }^{23}$. En este contexto, será relevante la presencia de músicos extranjeros, cuya labor además de asentar con fuerza el repertorio de moda, sirvió de vehículo entre la actividad propia de los espacios profanos y los religiosos. En el caso de Santiago, Izquierdo resalta la figura de Henry Lanza quien siendo maestro de capilla de la Catedral Metropolitana, desarrolló paralelamente una actividad como cantante en el principal teatro de la ciudad ${ }^{24}$. En la ciudad de Talca encontramos la figura del conocido director y compositor italiano Rafael Pantanelli, que luego de desarrollar una nutrida actividad musical en Santiago y el extranjero y, perder su fortuna en malogradas especulaciones mineras, se establece en la ciudad a principios de la década de 1860 . Sabemos además por las memorias de José Zapiola que fue su compañía la que inauguró el teatro de la Victoria en Valparaíso, junto a su esposa Clorinda Corradi Pantanelli, una de las más brillantes y famosas sopranos europeas del siglo ${ }^{25}$. El mencionado artista es un buen ejemplo de cómo músicos extranjeros desarrollaron una actividad musical paralela en los ámbitos religioso y profano, permeando constantemente elementos propios de la música teatral con el repertorio tradicional de las celebraciones religiosas. Pantanelli, compositor, director y empresario, fundó en 1869 una sociedad musical compuesta por la elite talquina "a fin de que pueda organizarse una orquesta en toda regla ${ }^{326}$ dirigida a desarrollar un repertorio principalmente operístico, tanto en los espacios profanos, como en las principales celebraciones religiosas.

\footnotetext{
${ }^{23}$ Merino M., Luis. "El surgimiento de la sociedad orfeón y el periódico las Bellas Artes. Su contribución al desarrollo de la actividad musical y de la creación musical decimonónica en Chile", Neuma 2/1 (2009): 12. ${ }^{24}$ Ver Izquierdo, José Manuel y Rojic, Lía. "Henry Lanza: Música, ópera, modernidad y religiosidad en la construcción cultural de la República chilena temprana (1840 -1860)”, Neuma 8/1 (2013): 10-29.

${ }^{25}$ Ver Zapiola, José. Recuerdos de treinta años (1810-1840). Santiago de Chile: Imprenta Victoria, 1881.

${ }^{26}$ El Artesano, Talca, 24 de abril de 1869. La mencionada sociedad, aparece con posterioridad indistintamente mencionada como Sociedad Musical o Club Musical.
} 
Así la presencia de músicos extranjeros y la visita de numerosas compañías extranjeras a la ciudad (incluso antes de antes de la construcción del teatro definitivo) reflejan la inquietud de la sociedad talquina por el desarrollo del arte musical. No nos extraña el gran interés que causara la llegada de Pantanelli a la ciudad y la organización del club musical con ambiciosos propósitos que se detallan en la prensa de la época:

Club Musical:

[...] anoche se celebró la primera reunion preparatoria, en la cual se acordo fijar para el domingo próximo para la instalación definitiva de la sociedad [...]

Como primera condicion que se va a exijir a cada socio, es el aprendisaje de un instrumento de música, instrumento que estará a elección del directorio, a fin de que pueda organizarse una orquesta en toda regla, consultando en lo posible las condiciones físicas del individuo. Se fija esto como condicion indispensable para ser miembro; porque la nueva sociedad solo tiene por esclusivo objeto la enseńanza i ejercicios de la música, i arreglar una orquesta más o menos completa y numerosa con la cual se pueda dar conciertos y solemnizar espectáculos públicos [... $]^{27}$.

Gracias a este testimonio no sólo podemos comprobar nuestra idea de que Pantanelli siguió desarrollando una nutrida actividad musical una vez establecido en Talca, sino que además nos permite conocer los objetivos de la nueva institución que corresponden cabalmente al sentido modernizador que conlleva la asociatividad de este tipo de instituciones. La sociedad talquina, agradecida de tan encomiable iniciativa, responde en buena medida aumentando el interés por la música, el cual se ve reflejado en la gran cantidad de avisos relacionados a venta de pianos, profesores de piano, canto y partituras en la prensa local, destacándose la visita recurrente de maestros extranjeros que dadas las noticias recibidas en otras latitudes, viajaban o decididamente se establecían en la ciudad ofreciendo sus servicios en los medios locales. El impacto de todo este movimiento musical es tal, que el año 1878, se instala en la ciudad la primera tienda exclusivamente de música, encargada de traer instrumentos, accesorios y partituras diversas por un miembro fundador de la ya reconocida Sociedad Musical de Rafael Pantanelli.

Música:

En la tienda del que suscribe se encuentra de venta un gran surtido de piezascanto, piano, violín, flauta, clarinete, violoncelo etc.

Tengo también instrumentos de todas las clases: Pianos, cuerdas i llaves para ellos, violines, clarinetes, armoniums, flautas etc.

I me encargo de hacer venir de Valparaíso cualquier instrumento que se desee... José Demarco ${ }^{28}$.

${ }^{27}$ El Artesano, Talca, 24 de abril de 1869.

${ }^{28}$ El Artesano, Talca, 24 de mayo de 1869. 
Pero la dinámica social producida en torno a tan variada actividad musical, dejó en evidencia un fenómeno del cual hasta ahora no teníamos noticia alguna, y refleja en buena medida el importante valor que se dio al cultivo del arte musical por sectores muy diferenciados socialmente en la época: La fundación de la Sociedad Musical de Artesanos en 1868.

La Sociedad Filarmónica de Artesanos, a diferencia del Club Musical de Pantanelli que estaba formado por personas pertenecientes a la élites de la ciudad, se constituye con numerosos aficionados de sectores medios que gustan de la música y varias manifestaciones artísticas más, reunidos en una organizada sociedad obrera. Las primeras noticias acerca de esta institución las encontramos en el periódico El Obrero Católico, que circula en la ciudad durante la década de 1860 en respuesta al periódico El Obrero, este último con una línea editorial muy marcada por el colectivismo proletario. La editorial, intentando hacer una manifestación de júbilo frente a tan encomiable iniciativa, demuestra una displicente mirada frente a los jóvenes obreros en comparación a los jóvenes de buena situación de la siguiente forma:

Filarmónica.

Sabemos que los artesanos de nuestro pueblo a fin de cultivar el espíritu de asociacion y de fraternidad, piensan organizar una sociedad de filarmónica para pasar las largas noches de invierno. Celebramos con entusiasmo esta idea que los honra altamente !Que dirá nuestra juventud elegante cuando los pobres artesanos saben proporcionarse entretenciones honestas, propias de la jente culta i de alto tono! ${ }^{29}$.

Las habladurías y desconfianzas de los sectores aristocráticos de la ciudad, frente a las actividades hechas por los miembros de la Sociedad Filarmónica, se ven reflejadas en continuos avisos en los diarios conservadores como el anterior citado, en respuesta a ello, la Sociedad publica un largo artículo donde da a conocer sus actividades en detalle y presenta como su director al señor Carlos Fletcher ${ }^{30}$, que ocupará el cargo brevemente, sólo hasta febrero de 1868, siendo sucedido por el señor Mateo José Sepúlveda ${ }^{31}$.

Si bien, la fundación de sociedades filarmónicas o clubes musicales no es privativa de la ciudad de Talca (Sociedad Filarmónica de Santiago 1826, Sociedad Orfeón de Santiago en 1868, Chillán, Copiapó y Valdivia), el caso de Talca cobra el mayor interés, ya que coexisten dos sociedades diferenciadas cultural y socialmente, pero con un proyecto común de reflejarse en la sociedad como modelo civilizatorio a través del arte musical. Es destacable tal interés por la música, puesto que permitió la coexistencia de dos de estas instituciones en una ciudad eminentemente periférica.

${ }^{29}$ El Obrero Católico, Talca, 25 de julio de 1868.

${ }^{30}$ El Artesano, Talca, 3 de diciembre de 1868.

${ }^{31}$ El Artesano, Talca, 7 de febrero de 1869. 


\section{CONCLUSIONES}

Luego de revisar la cuantiosa documentación conservada, que nos refleja la rica dinámica en torno a teatros e instituciones en la ciudad, podemos comprender que dicha actividad artística y social fue más allá que la pura representación estética de un repertorio determinado, sino que reflejó todo un modelo idealizado de sociedad. A lo largo de este trabajo, hemos señalado especialmente el valor simbólico que tuvo para la sociedad talquina que recibió el impacto modernizador de la temprana República, la actividad teatral y musical. Hemos expuesto que dicha valoración influyó directamente en varios aspectos: Primero, en las dinámicas de construcción de espacios de representación escénica, especialmente los teatros, como lugar en el que acuden los miembros de la sociedad y así autoafirmarse como ilustrados. En este sentido, hemos evidenciado el papel de la oligarquía talquina en la construcción y financiamiento de dichos espacios. Segundo, en la formación de orquestas, como un medio necesario para dichos fines. Tercero, en la presencia de actores y especialmente músicos italianos que tanto por su trayectoria como por su procedencia aseguraron una educación musical de prestigio. Cuarto, finalmente, en una asociatividad que permitió la continuidad de estos proyectos, que específicamente en Talca se dio en forma simultánea en grupos separados social y culturalmente. Por otra parte, la documentación consultada nos permite constatar que Talca era parte importante del circuito de companías teatrales y musicales extranjeras que circulaban por el país, influyendo con su presencia al servir de incentivo para la construcción y mantención de espacios que las acogieran. Además, hemos evidenciado el proceso de transformación del contenido de algunos espectáculos presentados en la ciudad, desde uno propio del tipo de diversión pública colonial, hacia uno que, a medida que transcurre la segunda mitad del siglo XIX, implica un ideal de refinamiento, encarnado por la ópera italiana, y la dramaturgia. Esperamos de esta manera contribuir en la reconstrucción de nuestra propia memoria artística y cultural, y generar nuevas propuestas y respuestas en pos de la historia regional.

\section{REFERENCIAS}

Beverley, Jhon. "El subalterno y los límites del saber académico". Subalternity and Representation: Arguments in Cultural Theory. Traducción de Marlene Beiza y Sergio Villalobos-Ruminott. Dhuram: Duke University Press, 1999.

García Canclini, Néstor. El teatro de las identidades. América y Europa: Seducción, suspicacia, confusión, 1999. 
Izquierdo, José Manuel y Rojic, Lía. “Henry Lanza: Música, ópera, modernidad y religiosidad en la construcción cultural de la república chilena temprana (1840 -1860)", Neuma 8/1 (2013): 10-29.

Merino M., Luis. "El surgimiento de la sociedad orfeón y el periódico las Bellas Artes. Su contribución al desarrollo de la actividad musical y de la creación musical decimonónica en Chile", Neuma 2/1 (2009): 10-43.

Opazo Maturana, Gustavo. Historia de Talca. Santiago de Chile. Imprenta Universitaria, 1942.

Pereira Salas, Eugenio. Historia del Teatro en Chile desde sus orígenes hasta la muerte de Juan Casacuberta 1849. Santiago de Chile: Editorial Universitaria, 1979.

Ramos Fuentes, José. "Música y sociedad en Talca antes del Concilio Vaticano II: Una aproximación histórico-social (1857-1916)”, Espacio Regional 9/1(2012): 93-107.

RodríguezSilva, Andrea. "Los orígenes del Teatro en Copiapó. Consumo, placer einstrucción, 1847-1867”. Tesis para optar al grado de Magíster en Historia, Mención en Historia de América. Facultad de Filosofía y Humanidades. Chile: Universidad de Chile, 2003. Disponible en: http://www.tesis.uchile.cl/tesis/uchile/2003/rodriguez_a/ $\mathrm{html} /$ index-frames.html [Consultado: el 10 de agosto de 2013].

Salinas, Maximiliano. "Comida, música y humor. La desbordada vida popular". En Rafael Sagredo y Cristián Gazmuri. Historia de la vida privada en Chile. Tomo 2. El Chile Moderno de 1840 a 1925. Buenos Aires: Aguilar, Altea, Taurus, Alfaguara S.A., (2005): 91-117.

Zapiola José. Recuerdos de treinta años (1810-1840). Santiago de Chile: Imprenta Victoria, 1881.

\section{Periódicos}

El Alfa, 1845.

El Eco de Talca, 1854.

El Emisario, 1857.

La Esperanza, 1860 y 1862.

El Artesano, 1867, 1868 y 1869.

El Obrero Católico, 1868. 